\title{
Possible Mechanisms for Turbofan Engine Ice Crystal Icing at High Altitude
}

\author{
Jen-Ching Tsao* \\ Ohio Aerospace Institute, Cleveland, OH 44142 \\ Peter Struk ${ }^{\dagger}$, Michael Oliver ${ }^{*}$ \\ NASA John Glenn Research Center, Cleveland, OH 44135
}

\begin{abstract}
A thermodynamic model is presented to describe possible mechanisms of ice formation on unheated surfaces inside a turbofan engine compression system from fully glaciated ice crystal clouds often formed at high altitude near deep convective weather systems. It is shown from the analysis that generally there could be two distinct types of ice formation: (1) when the "surface freezing fraction" is in the range of 0 to 1 , dominated by the freezing of water melt from fully or partially melted ice crystals, the ice structure is formed from accretion with strong adhesion to the surface, and (2) when the "surface melting fraction" is the range of 0 to 1 , dominated by the further melting of ice crystals, the ice structure is formed from accumulation of un-melted ice crystals with relatively weak bonding to the surface. The model captures important qualitative trends of the fundamental ice-crystal icing phenomenon reported earlier ${ }^{1,2}$ from the research collaboration work by NASA and the National Research Council (NRC) of Canada. Further, preliminary analysis of test data from the 2013 full scale turbofan engine ice crystal icing test ${ }^{3}$ conducted in the NASA Glenn Propulsion Systems Laboratory (PSL) has also suggested that (1) both types of ice formation occurred during the test, and (2) the model has captured some important qualitative trend of turning on (or off) the ice crystal ice formation process in the tested engine low pressure compressor (LPC) targeted area under different icing conditions that ultimately would lead to (or suppress) an engine core roll back (RB) event.
\end{abstract}

\section{Nomenclature}

$b \quad=$ relative heat factor, dimensionless

$\hat{b} \quad=$ modified relative heat factor, dimensionless

$\hat{c}_{0} \quad=$ specific ratio of ice particle kinetic heating to latent heat absorbed from melting, dimensionless

$c_{p, \text { air }}=$ specific heat of air, cal $/ \mathrm{g} \mathrm{K}$

$c_{p, w s}=$ specific heat of water at the surface temperature, cal $/ \mathrm{g} \mathrm{K}$

$h_{c} \quad=$ convective heat-transfer coefficient, cal $/ \mathrm{s} \mathrm{m}^{2} \mathrm{~K}$

$h_{G} \quad=$ gas-phase mass-transfer coefficient, $\mathrm{g} / \mathrm{s} \mathrm{m}^{2}$

IWC $=$ ice water content, $\mathrm{g} / \mathrm{m}^{3}$

LWC = liquid water content of melted ice, $\mathrm{g} / \mathrm{m}^{3}$

$M R \quad=$ ice crystal melt ratio, $=L W C_{t} / I W C_{i}$, dimensionless

$M_{\infty} \quad=$ local Mach number, dimensionless

$M M D=$ ice crystal median mass diameter, $\mu \mathrm{m}$

$M V D=$ water droplet median volume diameter, $\mu \mathrm{m}$

$\dot{m}_{e} \quad=$ mass flux of water evaporated per unit time, $1 \mathrm{bm} / \mathrm{ft}^{2} \mathrm{~s}$

$\dot{m}_{i m p}=$ mass flux of ice/liquid-water particle impinged per unit time, $1 \mathrm{bm} / \mathrm{ft}^{2} \mathrm{~s}$

* Principal Research Scientist, 21000 Brookpark Rd., MS 11-2, AIAA Associate Fellow.

${ }^{\dagger}$ Research Scientist, Icing Branch, 21000 Brookpark Rd., MS 11-2, AIAA Senior Member.

* Aerospace Engineer, Icing Branch, 21000 Brookpark Rd., MS 11-2, AIAA Member. 


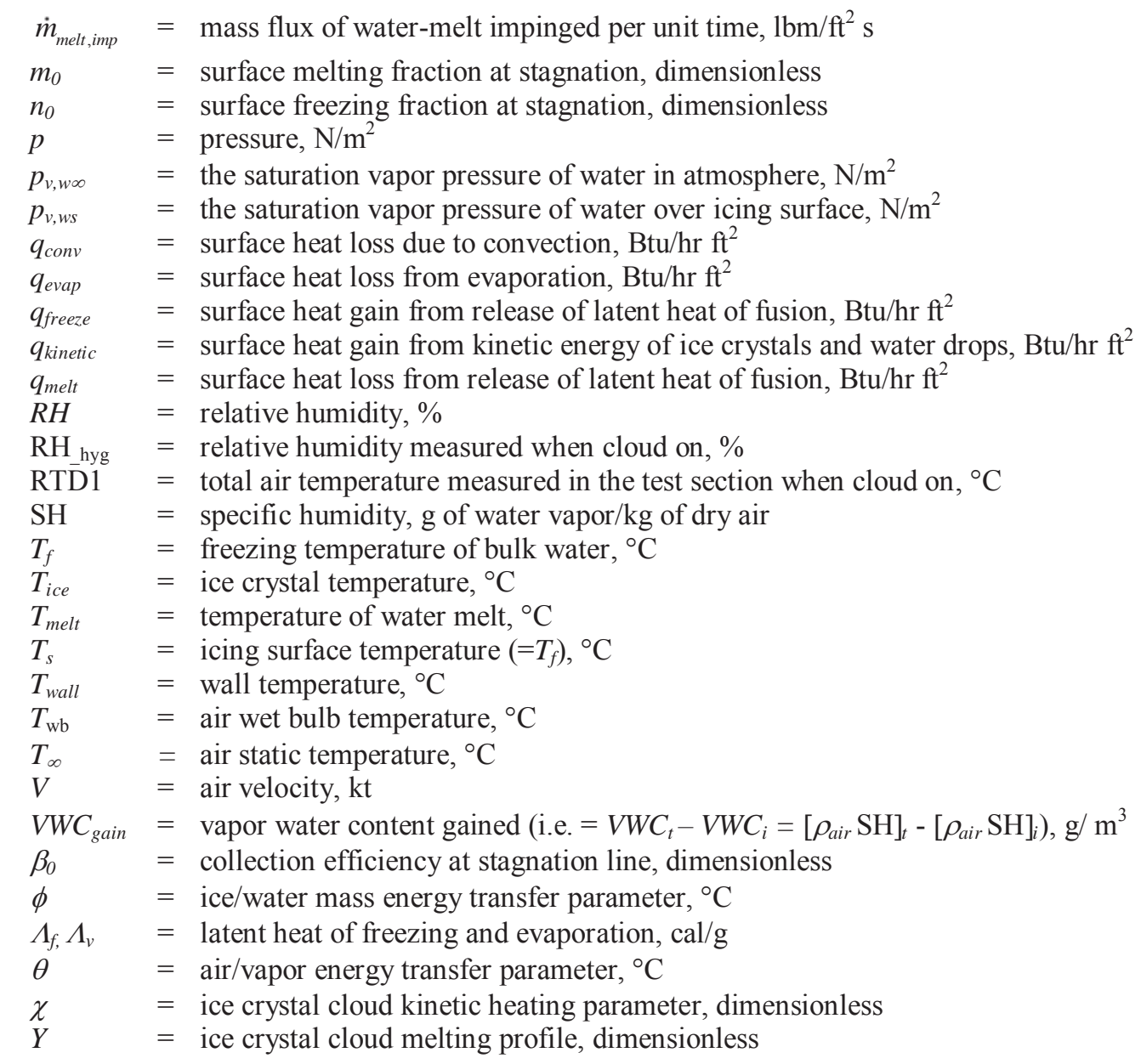

Subscripts

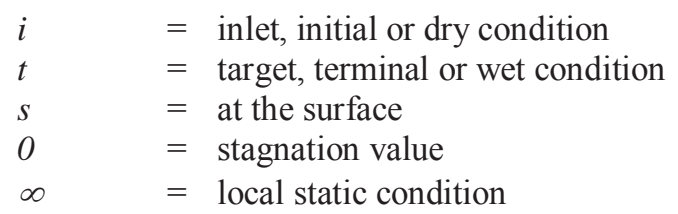

Superscripts

$\begin{array}{ll}* \quad & =\text { threshold value } \\ \sim & =\text { threshold value }\end{array}$

\section{Introduction}

Uumerous turbofan engine power-loss events have been observed (some as recent as $2013^{\S}$ ) on both commuter and large transport aircraft near large deep convective weather systems at high altitudes ${ }^{4}$. The deep convective updraft core can bring large amounts of condensed water from the surface to the cloud top. In theory the predicted maximum ice water content (IWC) above the freezing level in these clouds could reach up to about $9 \mathrm{~g} / \mathrm{m}^{3}$ at around 30,000 ft. In addition, from more recent measurement data available on microphysical properties of deep convective clouds it appears that fully glaciated ice crystals have been dominated in the deep convection above the freezing level and the ice mass has been concentrated at sub-200 $\mu \mathrm{m}$ sizes, and very little super-cooled liquid water content $(L W C)$ has been observed.

\footnotetext{
$\S$ Aviation Safety Network News, "Russia investigates serious engine icing incident on Boeing 747-800," the link to the news website is: http://news.aviation-safety.net/2013/08/20/russia-investigates-serious-engine-icing-incident-on-boeing-747-800/20, reported on August 2013
} 
Mason et al. ${ }^{4}$ have proposed a hypothesis for possible ice accretion due to ice crystal ingestion based on the instrumented flight-testing data collected in commuter and transport aircraft engine events. The hypothesis basically recognized that ingested ice crystals could begin to melt causing mixed-phase conditions within the compression system passage of the engine. This mixed-phase water mass would impinge and accrete on unheated surfaces within the engine where the local air temperature was significantly higher than freezing before entering the cloud. This ice crystal icing inside the engine compression system has been shown to create flow blockage and hardware damage, as shown in Ref. 3, such that the engine could no longer function properly. The hypothesis specifically stated that liquid water is a necessary condition locally for ice accretion to continue. Furthermore, it was believed that this ice crystal accretion phenomenon is not unique to commuter or transport aircraft engine type and therefore it was expected that certain common physical mechanisms for ice crystal accretion on all jet engines should exist.

To better understand the fundamental aspects of ice crystal accretion physics and possible influence of high concentrations of ice crystals on engine performance and operability, NASA and NRC of Canada have begun a series of fundamental icing physics studies ${ }^{1,2}$ to examine the physical mechanisms of ice accretion on surfaces exposed to fully glaciated ice crystal and mixed-phase conditions similar to those believed to be encountered during engine power-loss events. These investigations were mainly experimental utilizing the NRC Research Altitude Test Facility (RATFac) and a special cascade wind tunnel, see Figures 1-2, to create semi-realistic icing local flow conditions inside a turbofan engine low pressure compressor (LPC) region to (1) observe how ice crystal accretion process takes place, (2) identify the onset conditions and the corresponding threshold limits to turn on or turn off the accretion and finally (3) explore the inter-relation of relevant physical variables associated with engine ice crystal icing processes.

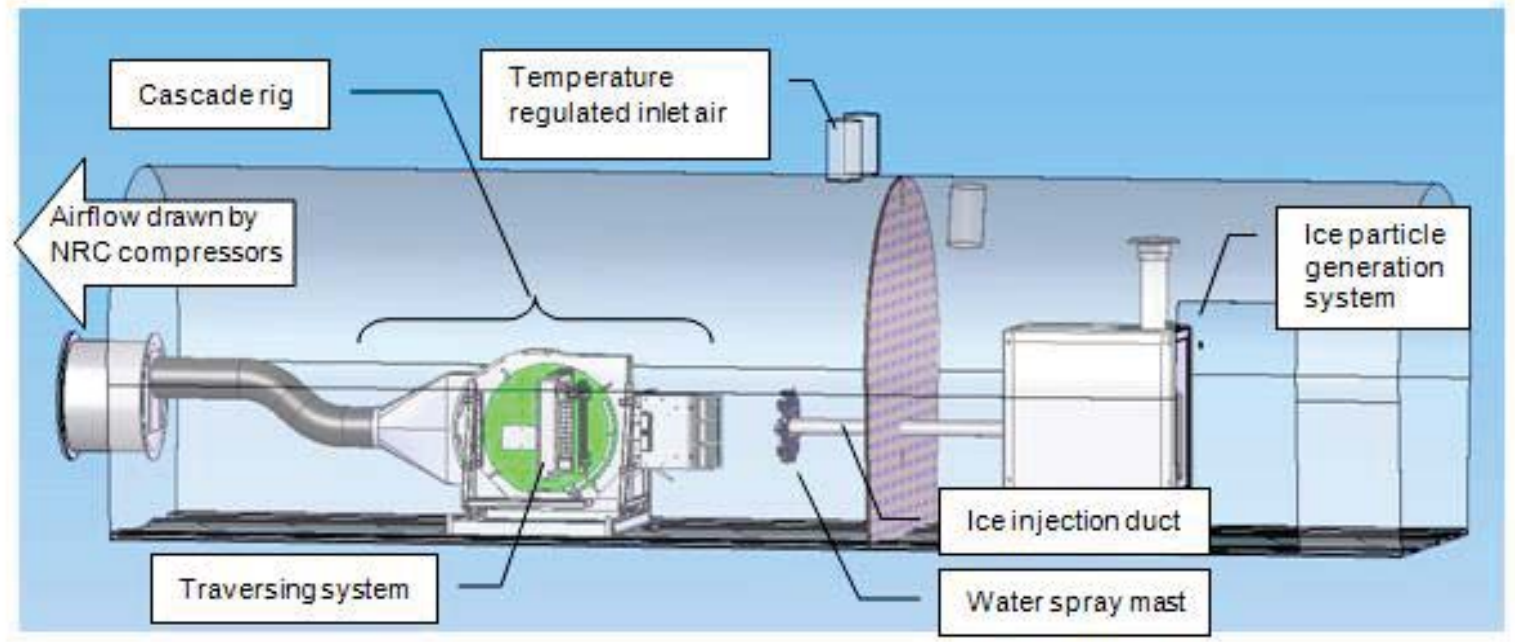

Figure 1. Ice crystal test system with cascade wind tunnel installed in NRC RATfac

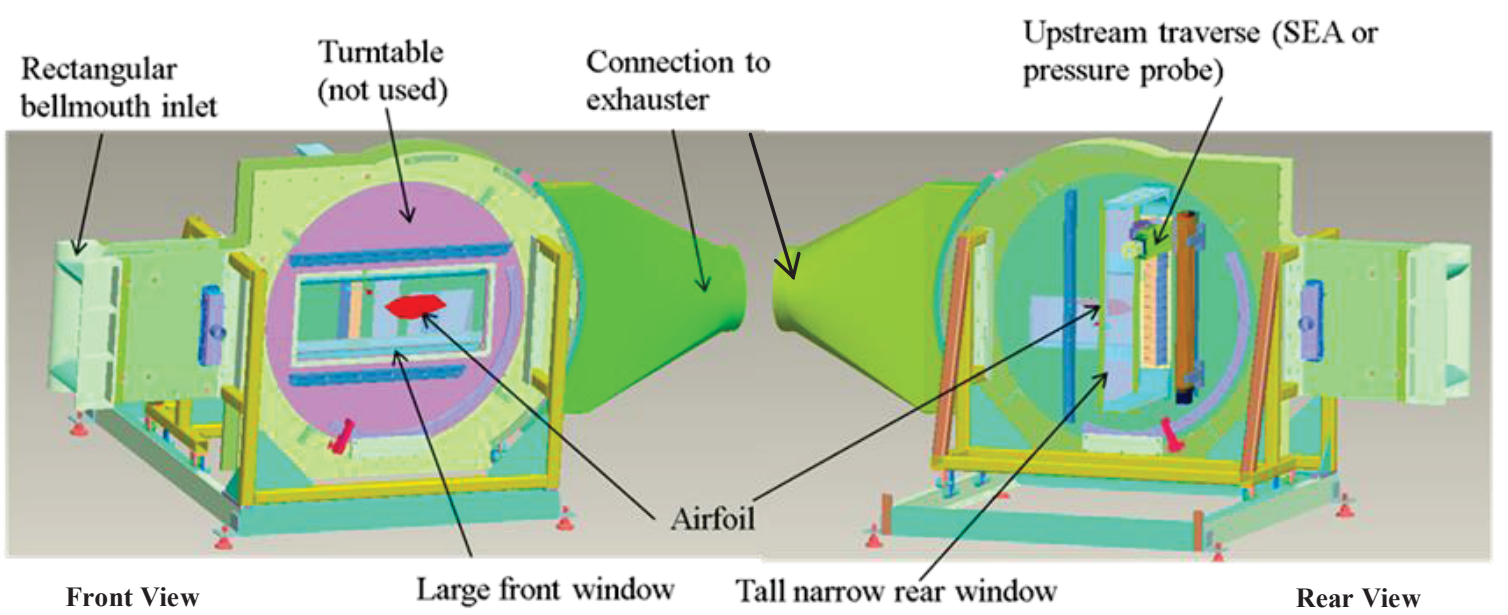

3

Figure 2. The cascade wind tunnel showing experimental configuration including airfoil 
Key findings from those early studies included: (1) the air wet bulb temperature, $T_{w b}$, was identified to be an effective parameter to represent the air/water vapor mixture (i.e. humid air) temperature for studying ice-crystal icing process. In particular, it was shown that higher altitude (i.e. decreasing pressure) with lower humidity inside an engine with ingested ice crystals enhances the evaporative cooling of the local air flow and the compression system passage wall temperatures and reduces the initial wet bulb temperature to a lower asymptote in a time scale of about one half to a few minutes into the spray, (2) two distinct types of ice formation were observed on an unheated icing surface. When the (total) air wet bulb temperature $T_{w b, 0}$ was above freezing $\left(\geq+2^{\circ} \mathrm{C}\right)$ there seemed to exist a corresponding IWC threshold $\left(I W C^{*}\right)$ in order to have some ice formed on the surface by the accumulation of un-melted ice crystals with relatively weak surface bonding. As a result, a large piece of shed ice was frequently observed. Furthermore for any given $I W C>I W C^{*}$ at the prescribed $T_{w b, 0}$, the overall ice size and the leading edge ice growth rate (before any big shedding) became larger as $I W C$ increased. Interestingly it was also observed that for the largest IWC value tested (i.e. $\left.17 \mathrm{~g} / \mathrm{m}^{3}\right)$, there was a corresponding wet bulb temperature threshold $\left(T_{w b, 0}{ }^{*}\right)$ that when exceeded could eliminate the ice formation from the surface. For example Runs $522 \& 524$ of Ref. 2, the $T_{w b, 0}$ was raised from about $2.7^{\circ} \mathrm{C}$ to $9.3^{\circ} \mathrm{C}$ to suppress the ice formation completely as shown in Figure 3 .

However when $T_{w b, 0}$ was just below freezing $\left(\sim-2^{\circ} \mathrm{C}\right)$ the ice was formed by accretion of water melt (similar to

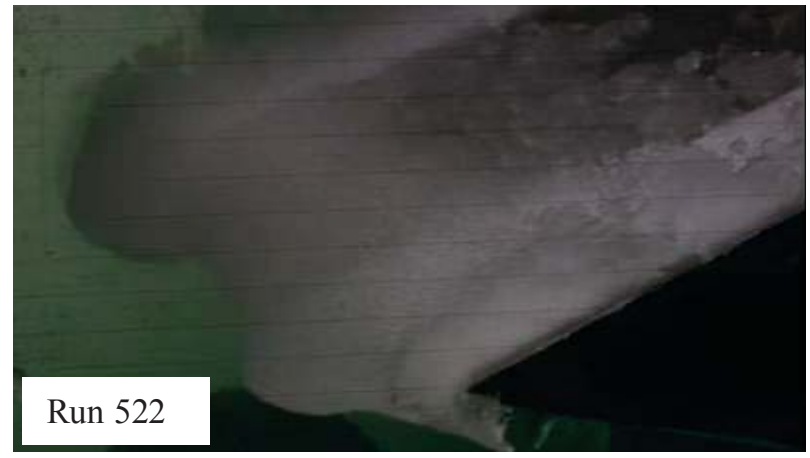

$\mathrm{M}_{\infty}=0.25, \mathrm{P}_{0}=6.5 \mathrm{psia}, \mathrm{IWC}=17 \mathrm{~g} / \mathrm{m}^{3}, \mathrm{~T}_{\mathrm{wb}, 0}=2.7^{\circ} \mathrm{C}$.

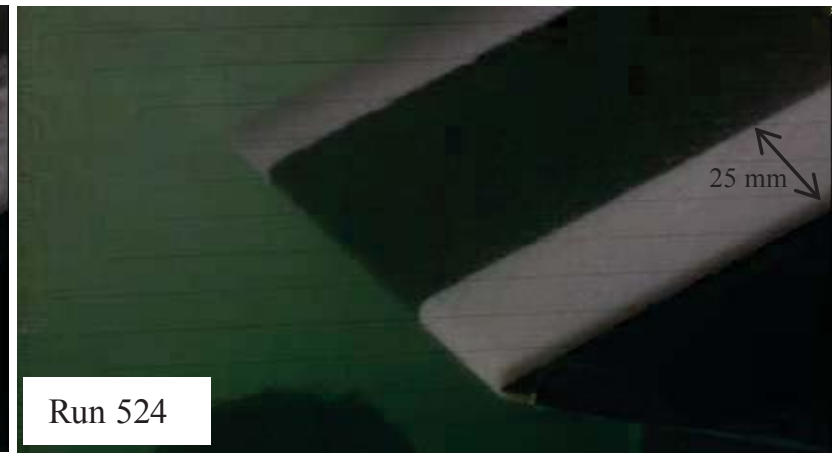

$M_{\infty}=0.25, P_{0}=6.5$ psia, $\mathrm{IWC}=17 \mathrm{~g} / \mathrm{m}^{3}$ only, $\mathrm{T}_{\mathrm{wb}, 0}=9.3^{\circ} \mathrm{C}$.

Figure 3. Large ice formation with frequent shedding was observed in Run 522. For Run 524 no ice was observed by raising the $T_{w b, 0}$ to $9.3^{\circ} \mathrm{C}$.

the super-cooled liquid water icing process) with strong adhesion to the surface. No large ice shedding was noticed but sizable mass of ice and water (e.g. small glaze ice feathers and surface runback water) was stripped off from the ice structure formed in part due to the known effect of ice erosion and surface water splash-off. This loss effect was further amplified as local Mach number increased. For example Runs $512 \& 504$ of Ref. 2, the $T_{w b, 0}$ was $-2^{\circ} \mathrm{C}$, and a very glazy ice accretion was observed for Run 512 at $M_{\infty}=0.25$ but a rime-to-glaze transition type of ice accretion was observed for Run 504 at $M_{\infty}=0.4$, as shown in Figure 4.

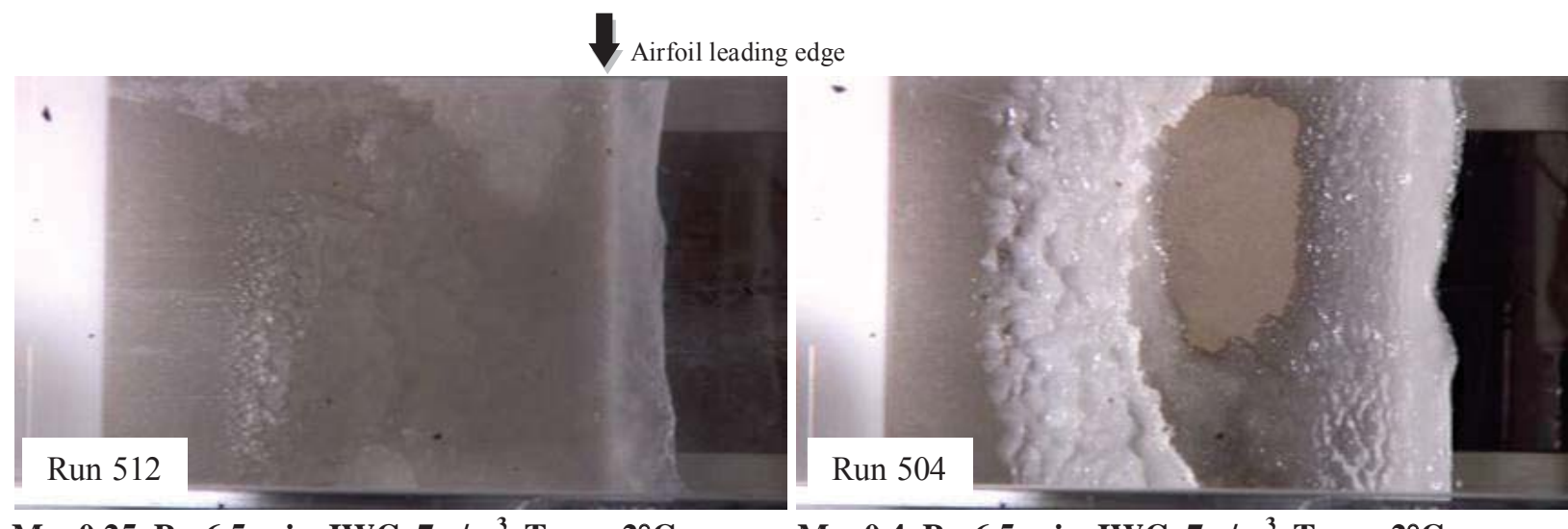

$\mathrm{M}_{\infty}=0.25, \mathrm{P}_{0}=6.5 \mathrm{psia}, \mathrm{IWC}=7 \mathrm{~g} / \mathrm{m}^{3}, \mathrm{~T}_{\mathrm{wb}, 0}=-2^{\circ} \mathrm{C} . \quad \mathrm{M}_{\infty}=0.4, \mathrm{P}_{0}=6.5 \mathrm{psia}, \mathrm{IWC}=7 \mathrm{~g} / \mathrm{m}^{3}, \mathrm{~T}_{\mathrm{wb}, 0}=-2^{\circ} \mathrm{C}$.

Figure 4. Two different ice accretions were observed for $T_{w b, 0}=-2^{\circ} \mathrm{C}$ at local $M_{\infty}=0.25 \& 0.4$ (top view). 


\section{Run 512}

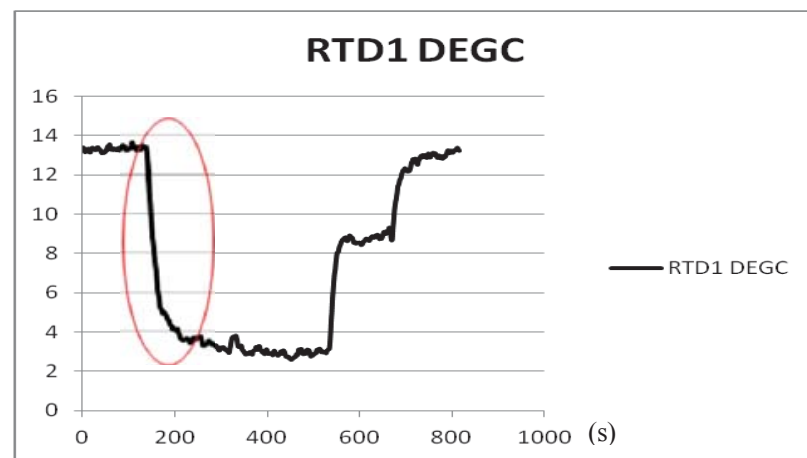

Taking $77 \mathrm{sec}$ for $\mathrm{T}_{\mathbf{0}}$ to cool from 13.45 to $3.62 \mathrm{deg} \mathrm{C}$

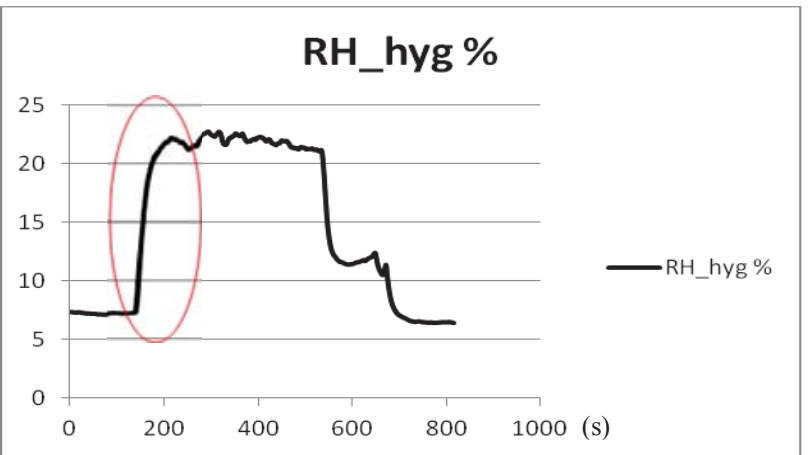

Taking 79.2 sec for $\mathrm{RH}$ to rise from 7.1 to $21.8 \%$

Figure 5 Evolution of total air temperature and relative humidity measurements in the test section.

The calculated leading edge ice thickness from LEWICE2D without the mass loss was an order of magnitude larger than the experimental images indicated. This type of mass loss phenomenon has been reported earlier by Kamel Al-KHalil ${ }^{5}$ in his 2003 experimental study of mixed-phase icing effect on thermal ice protection systems (IPS), and lastly (3) there seemed to be a strong thermal interaction between the ingested ice crystals and the initial warm local airflow environment. As the IWC cloud entered the test section, the dry air total temperature started dropping and the water vapor content was rising to a new asymptotic value, as shown in Figure 5 for Run 512 of Ref. 2. This observation was significant and implied that the dry conditions, measured prior to the start of an icing test, do not accurately represent the conditions near the test article while the cloud is on.

The focus of the current study is to present the thermodynamic model developed specifically for engine ice crystal icing and some analysis results from the model will be validated with aforementioned experimental data trend from Ref. 1 and 2. Finally, a selected number of engine LPC local flow simulation results from COMDES ${ }^{6,7}$, GlennHT, LEWICE3D and surface temperature measurement data from Ref. 3 will be used to assess the validity and applicability of the model to simulate critical ice formation processes related to a full engine icing event. The validated model will become the theoretical ground for new altitude scaling method development ${ }^{8}$ to support future scaling tests as well as preparatory experimental work at RATFac and PSL including ice-crystal cloud characterizations, new test rig and new test article development, and new imaging methods for ice shape characterization needed in altitude scaling tests.

\section{The Thermodynamic Model for Ice Crystal Icing}

This new thermodynamic model is primarily based on the scaling work originally done by Ruff ${ }^{9}$ and later extended by Anderson ${ }^{10}$ and Anderson and Tsao ${ }^{11}$ for super-cooled liquid water icing in both Appendix C and SLD regimes. The expressions for the parameters used will be presented here without much discussion. Therefore, readers who are interested in the physical descriptions and detailed derivations of these parameters are referred to Ref. 10 and 11 and the references given therein. Some modifications are made in the surface energy balance equation to account for possible interactions between the local air flow within the compression system flow passage and the ingested ice crystals from the engine inlet and they will be described in the discussion below.

\section{A. Model Assumptions}

Currently the model only considers the engine ice crystal icing phenomenon for a fully glaciated ice crystal cloud which is the most prevalent cloud characteristic in or around a large deep convective weather system at high altitude $^{4}$. Figure 6 illustrates the notional schematics of ice crystal particle path through an engine fan and LPC region. When the surface energy balance analysis is applied to a selected stagnation location of a LP compressor component, e.g. a geared turbofan engine $2^{\text {nd }}$ exit guide vane leading edge (i.e. EGV2 LE), the model assumes or considers:

- local air flow is steady relative to accretion process,

- accretion is quasi-steady,

- fully glaciated ice particle cloud initially with single particle size, 
- no $L W C$ supplement (i.e. fully glaciated ice crystal cloud at inlet)

- when ice particles experience some melting, $T_{i c e}=T_{\text {melt }}=T_{f}$ (i.e. $0<M R<1$ ),

- when $M R=0$ (no melting), $T_{i c e, i}<T_{i c e}<T_{f}$,

- when $M R=1$ (fully melted), $T_{f}<T_{\text {melt }}<T_{0}$,

- for partially-melted ice particle cloud, $L W C_{t}=I W C_{i} * M R, I W C_{t}=\left[I W C_{i} *(1-M R)\right]-V W C_{\text {gain, }}$,

- on unheated surface ( $T_{\text {wall }}$ could be fairly hot initially),

- $T_{s}=T_{f}$ when glaze ice accreted or accumulated on surfaces.

\section{B. The Surface Energy Balance Equation}

Once ice cloud is on, air starts cooling down, SH increasing and then asymptotic to a steady state
$\mathrm{LWC}_{\mathrm{t}}, \mathrm{MVD}_{\mathrm{t}}$ (" local LPC condition) $\mathrm{IWC}_{\mathrm{t}}, \mathrm{MMD}_{\mathrm{t}}$

Melt Ratio (Mn

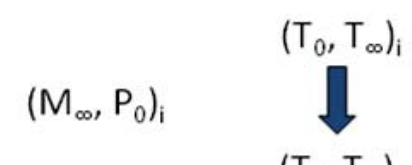

$(\mathrm{SH}, \mathrm{RH})_{\mathrm{i}}$

$$
\left(T_{0}, T_{\infty}\right)_{t}
$$

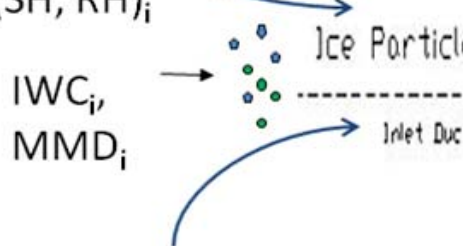

Inlet/Initial/Dry (subscript i)

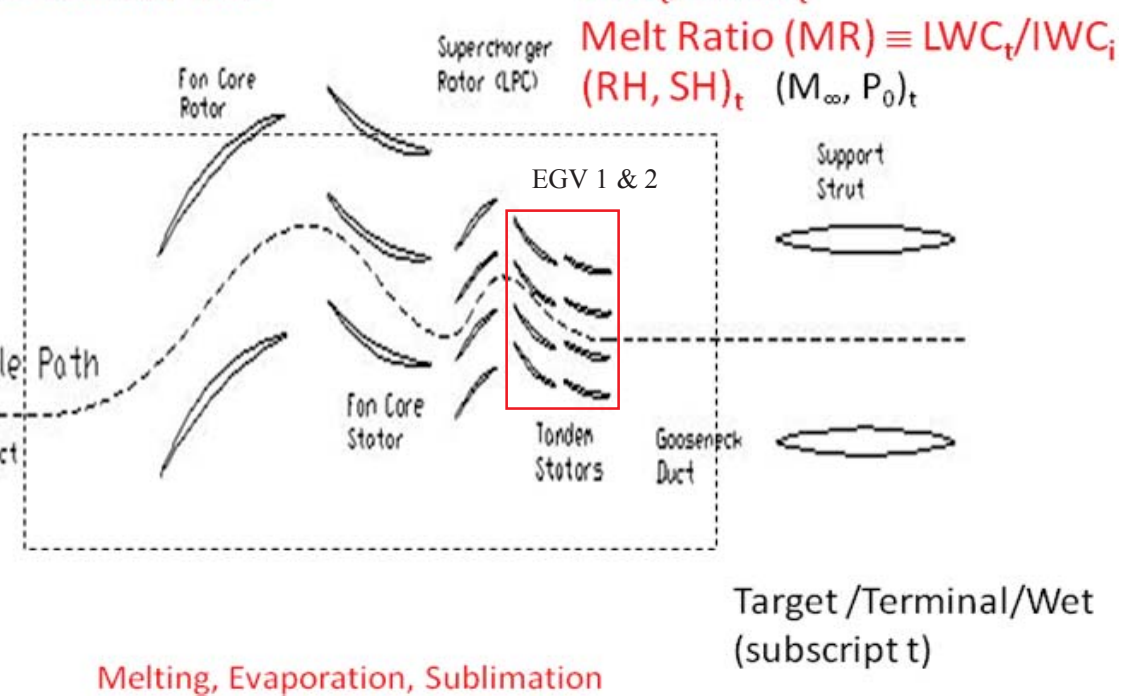

Melting, Evaporation, Sublimation

Figure 6. The schematics of ice particle path through an engine fan and LPC region.

As duly noted in Ref. 1 and 2, there are two distinct types of ice growth mechanism in ice crystal icing. It is advantageous to present the corresponding equation accordingly from applying the mass and energy conservation laws on the icing surface. Here only the final governing equations and key expressions of parameters are presented without much discussion for brevity. These two types of ice growth mechanism are described as follows:

(1) Freezing dominated process on surface when cooling > heating (i.e. $0 \leq n_{0} \leq 1$ )

$$
q_{\text {evap }}-q_{\text {conv }}-q_{\text {kinetic }}=q_{\text {freeze }}
$$

where

$$
\begin{gathered}
q_{\text {evap }}=\dot{m}_{e} L_{v}=h_{G} \frac{\left(\left[\frac{p_{v, \text { ws }}}{T_{\infty}}-\left(\frac{P_{0}}{T_{0}}\right) \frac{p_{v, \text { wo }}}{P_{\infty}}(R H)\right]\right)}{\frac{1}{0.622}\left(\frac{P_{0}}{T_{0}}\right)-\left(\frac{p_{v, w s}}{T_{\infty}}\right)} \Lambda_{v}, \\
q_{c o n v}=h_{c}\left(T_{\infty}+V_{\infty}^{2} / 2 C_{p, \text { air }}-T_{s}\right), \\
q_{\text {kinetic }}=\dot{m}_{\text {imp }, t} \frac{\left(V_{\infty}\right)^{2}}{2}=\left(I W C_{i}-V W C_{\text {gain }}\right) \cdot \beta_{0} \cdot V_{\infty} \cdot\left(1-n_{\text {loss }}\right)_{0} \cdot \frac{\left(V_{\infty}\right)^{2}}{2}, \\
q_{\text {freeze }}=\dot{m}_{\text {melt }, \text { imp }} \cdot n_{0} \cdot \Lambda_{f}=\left(I W C_{i} \cdot M R\right) \cdot \beta_{0} \cdot V_{\infty} \cdot\left(1-n_{\text {loss }}\right)_{0} \cdot n_{0} \cdot \Lambda_{f} .
\end{gathered}
$$


Substituting the expressions for various heat flux terms listed above into Eq. (1) it can be rewritten in the following form

$$
n_{0}=\left(\frac{C_{p, w s}}{(M R) \cdot \Lambda_{f}}\right)\left(\frac{I W C_{i}-V W C_{g a i n}}{I W C_{i}}\right)\left(\phi+\frac{\theta_{0}}{b_{0}}\right)
$$

The surface freezing fraction is formally defined as the ratio of the amount of water that freezes at a given surface location to the total amount of water that impinges at that location. The key terms in this formulation include $\phi$ and $\theta_{0}$, which have dimensions of temperature and relate to the ice/water mass energy transfer and air/vapor energy transfer, and $b_{0}$, the relative heat factor, which was first introduced by Tribus, et al. ${ }^{12}$

$$
\begin{gathered}
\phi=\left(-\frac{V_{\infty}^{2}}{2 c_{p, w s}}\right), \\
\theta_{0}=\left(T_{s}-T_{\infty}-\frac{V_{\infty}^{2}}{2 c_{p, a i r}}\right)+\frac{h_{G}}{h_{c}}\left[\frac{\frac{p_{v, w s}}{T_{\infty}}-\left(\frac{P_{0}}{T_{0}}\right) \frac{p_{v, w \infty}}{P_{\infty}}(R . H .)}{\frac{1}{0.622}\left(\frac{P_{0}}{T_{0}}\right)-\left(\frac{p_{v, w s}}{T_{\infty}}\right)}\right] \Lambda_{v}, \\
b_{0}=\left(\frac{\dot{m}_{\text {imp }, t} C_{p, w s}}{h_{c}}\right)=\frac{\left(I W C_{i}-V W C_{g a i n}\right) \cdot \beta_{0} \cdot\left(1-n_{\text {loss }}\right)_{0} \cdot V_{\infty} \cdot C_{p, w s}}{h_{c}} .
\end{gathered}
$$

With some algebraic manipulations, Eq. (2) can be rewritten as

$$
n_{0}=\frac{1}{\hat{b}_{0}}\left(T_{s}-T_{w b, 0}\right)-\hat{c}_{0}
$$

in which $T_{w b, 0}$ denotes the air total wet bulb temperature and is given as

$$
T_{w b, 0}=\left(T_{\infty}+\frac{V_{\infty}^{2}}{2 c_{p, a i r}}\right)-\frac{h_{G}}{h_{c}}\left[\frac{\frac{p_{v, w s}}{T_{\infty}}-\left(\frac{P_{0}}{T_{0}}\right) \frac{p_{v, w \infty}}{P_{\infty}}(R . H .)}{\frac{1}{0.622}\left(\frac{P_{0}}{T_{0}}\right)-\left(\frac{p_{v, w s}}{T_{\infty}}\right)}\right] \Lambda_{v},
$$

and

$$
\begin{gathered}
\hat{b}_{0}=b_{0}\left(\frac{(M R) \Lambda_{f}}{C p_{w}}\right)\left(\frac{I W C_{i}}{I W C_{i}-V W C_{\text {gain }}}\right)=\frac{\dot{m}_{i m p, t}(M R) \Lambda_{f}}{h_{c}}\left(\frac{I W C_{i}}{I W C_{i}-V W C_{\text {gain }}}\right), \\
\hat{c}_{0}=\left(\frac{V_{\infty}^{2} / 2}{(M R) \Lambda_{f}}\right)\left(\frac{I W C_{i}-V W C_{\text {gain }}}{I W C_{i}}\right) .
\end{gathered}
$$

One can show from Eq. (3) that both $T_{w b, 0}$ and $M R$ can affect the accretion process but they do not uniquely determine the value of $n_{0}$. The $n_{0}$ depends on other important icing surface quantities like $h_{c}, \beta_{0}$ and $n_{\text {loss. }}$ There are many combinations of $T_{w b, 0}$ and $M R$ that could have the same freezing fraction $n_{0}$. It is also noted that for a given local thermal profile, i.e. fixed $T_{w b, 0}$ and $M R$, the value of freezing fraction $n_{0}$ will decrease as one increases $I W C$ 
load. Similar behaviors were observed in super-cooled water icing. This strongly suggests that the most important parameter affecting the ice crystal accretion process is the freezing fraction. In addition, $\underline{\mathbf{b} y}$ letting $\boldsymbol{n}_{0} \underline{=} \mathbf{0}$, a total wet bulb temperature threshold is obtained

$$
\tilde{T}=T_{s}-\hat{b}_{0} \cdot \hat{c}_{0}=T_{f}-\hat{b}_{0} \cdot \hat{c}_{0} .
$$

It should be noted that some freezing of water melt would occur on surface if $T_{w b, 0}<\tilde{T}$ whereas some melting of ice particle would occur on surface if $T_{w b, 0}>\tilde{T}$.

(2) Melting dominated process on surface when heating > cooling (i.e. $0 \leq m_{0} \leq 1$ )

$$
q_{\text {kinetic }}+q_{\text {conv }}-q_{\text {evap }}=q_{\text {melt }}
$$

Carrying out similar substitution procedures as described above, the surface melting fraction, formally defined as the ratio of the amount of ice that melts at a given surface location to the total amount of ice that impinges at that location, at stagnation can be rewritten from Eq. (5) as

$$
m_{0}=\frac{M R}{\hat{b}_{0}\left(1-M R-\left(\frac{V W C_{\text {gain }}}{I W C_{i}}\right)\right)}\left(T_{w b, 0}-T_{s}\right)+\frac{M R}{\left(1-M R-\left(\frac{V W C_{\text {gain }}}{I W C_{i}}\right)\right)} \hat{c}_{0}
$$

Similar to the freezing dominated process, Eq. (6) shows that both $T_{w b, 0}$ and $M R$ still affect the ice build-up process but they do not uniquely determine the value of $m_{0}$. Further, for a given $T_{w b, 0}$ and $M R$, as one increases IWC load, $m_{0}$ becomes smaller value $(\rightarrow 0)$ and the surface ice build-up will increase (both in size and rate). Likewise, for a given IWC cloud, as $T_{0}$ rises, $m_{0}$ becomes greater $(\rightarrow 1)$ and the surface ice formation will diminish. Asymptotically the surface ice growth is proportional to $\left(1-m_{0}\right)$.

To further understand whether in this regime the ice crystal icing phenomenon could be possibly turned on (i.e. $\left.m_{0}<1\right)$ or turned off $\left(m_{0}=1\right)$ by simply changing certain key variables, a special case of $\boldsymbol{m}_{0}=\mathbf{1}$ (i.e. fully melted condition) is studied with Eq. (6) and it is found that there exists an ice/water mass flux threshold to survive a complete melting on any given local stagnation surface

$$
\dot{m}_{i m p, t}^{*}=\frac{Y h_{c}\left(T_{s}-T_{w b, 0}\right)}{\chi \Lambda_{f}}
$$

in which

$$
\chi=\left[\left(\frac{Y}{\Lambda_{f}}\right)\left(\frac{V_{\infty}^{2}}{2}\right)-1\right]=Y\left(\frac{M_{\infty}^{2}}{\Lambda_{f}}\right)\left(\frac{\gamma}{2} R T_{\infty}\right)-1, \quad Y=\frac{\left(I W C_{i}-V W C_{\text {gain }}\right)}{I W C_{i}\left[1-M R-\left(\frac{V W C_{\text {gain }}}{I W C_{i}}\right)\right]} .
$$

There are three distinctly different types of physical parameters involved to determine this threshold:

1. $h_{c}$, representing the local surface convective heat transfer characteristics. The greater the local convective heat transfer is the larger the threshold would become. This suggests that with lower $h_{c}$ design stagnation regions inside the engine LPC the local surface might not have enough thermal margin to melt all possible impinging ice crystals for a given engine operation set point.

2. ( $\left(T_{w b, 0}-T_{s}\right)$, which represents the actual melting potential from air total wet bulb temperature to ice melting temperature. For a given engine LPC thermal profile, the lower the air pressure and water vapor content at higher flight altitude the smaller the air total wet bulb temperature becomes. Consequently it lessens the available melting potential inside the LPC which means the threshold would be lower. Unless the engine will increase its N1 setting or the aircraft will lower its flight altitude to raise its local air temperature, the ice crystal icing is likely to occur on surfaces with lower threshold. 
3. $\chi$ and $Y$, which are non-dimensional parameters denoting the ice crystal cloud kinetic heating and its melting profile right before impact. The net effect of this term $(Y / \chi)$ parametrically shows that the threshold will increase its value if the impinging IWC cloud could experience larger kinetic heating due to higher local inviscid flow velocity or the IWC cloud could have greater melting before impact. As a result, ice crystal icing would be more likely to occur at locations where the local inviscid flow velocity becomes slower or in engine operation conditions that do not promote more melting of ice particles early inside the LPC right before their impact. (e.g. the high altitude test points like DP 908 and SR-3 from the PSL engine icing test, see Ref. 3, 6 and 7)

Now considering for a given warm air total wet bulb temperature $T_{w b, 0}\left(>0{ }^{\circ} C\right)$, from Eq. (7), it is shown that there exists a $I W C_{i}$ threshold to allow some ice to remain on the surface and it is written as

$$
I W C^{*}=V W C_{\text {gain }}+\frac{h_{c}\left(T_{s}-T_{w b, 0}\right)}{\chi \cdot \Lambda_{f} \cdot \beta_{0} \cdot V_{\infty} \cdot\left(1-n_{\text {loss }}\right)_{0}} .
$$

It suggests that if $I W C_{i} \leq I W C^{*}$, no ice could survive the melting but if $I W C_{i}>I W C^{*}$, some ice build-up would remain on the surface. As for a given $I W C_{i}$ cloud, Eq. (7) also shows that there exists a $T_{w b, 0}$ threshold to melt all the ice on local surface. This wet bulb temperature threshold is written as

$$
T^{*}=T_{s}-\frac{\chi \Lambda_{f} \dot{m}_{i m p, t}}{Y h_{c}} .
$$

Similarly it suggests that if $T_{w b, 0} \geq T^{*}$, no ice could survive the melting but if $T_{w b, 0}<T^{*}$, some ice build-up would remain on the surface.

\section{Model Analysis and Comparison with Existing Experimental Data}

In this section, some model analysis results are compared with aforementioned experimental data trend observed from Ref. 1-3. The results are further divided into two parts:

\section{A.NRC RATfac Test Data - Local Flow Simulation}

The Runs 506, 522, 524 and 530 were conducted on March 9, 10 and 11, 2011 separately with condition listed below in Table 1. For Run 506, the initial $T_{w b, 0}$ was set to be $-2^{\circ} \mathrm{C}$. During the 6 minutes of $I W C$ only spray some ice crystal accretion was formed on the wedge model mid-span leading edge surface with no large ice shedding observed. The thermocouple reading from the leading edge location was fluctuating around $(-0.8,0.2)^{\circ} \mathrm{C}$. Applying the Run 506 test condition to Eq. (4) it was shown that with $T_{w b, 0}=-2{ }^{\circ} C, M R=0.1$, and estimated $n_{\text {loss }}=0.92$, the total wet bulb temperature threshold is about

$$
\tilde{T}=-0.8^{\circ} \mathrm{C} \text {. }
$$

Since the initial $T_{w b, 0}$ set value is less than the threshold, some freezing of water melt would occur on surface.

Table 1 Run 506, 522, 524 and 530 test conditions

\begin{tabular}{|l|l|l|c|c|c|c|}
\hline Test Conditions & & & $\begin{array}{c}\text { Run 506 } \\
(03-09-11)\end{array}$ & $\begin{array}{c}\text { Run 522 } \\
(03-10-11)\end{array}$ & $\begin{array}{c}\text { Run 524 } \\
(03-10-11)\end{array}$ & $\begin{array}{c}\text { Run 530 } \\
(03-11-11)\end{array}$ \\
\hline & & & & & & \\
\hline Ice Water Content & $I W C_{i}$ & $\mathrm{~g} / \mathrm{m}^{3}$ & 7.0 & 17.0 & 17.0 & 3.0 \\
\hline Ice Particle MMD & $M M D$ & $\mu \mathrm{m}$ & 115 & 115 & 115 & 115 \\
\hline Liquid Water Content & $L W C_{i}$ & $\mathrm{~g} / \mathrm{m}^{3}$ & 0.0 & 0.0 & 0.0 & 0.0 \\
\hline Total Temperature & $T_{0}$ & ${ }^{\circ} \mathrm{C}$ & 13 & 20 & 23.5 & 23 \\
\hline Total Pressure & $P_{0}$ & $\mathrm{psia}$ & 6.5 & 6.5 & 6.5 & 6.5 \\
\hline Relative Humidity & $R H$ & $\%$ & 8.0 & 13.0 & 27.0 & 9.0 \\
\hline Total Wet Bulb temperature & $T_{\mathrm{wb}, 0}$ & ${ }^{\circ} \mathrm{C}$ & -2.0 & 3.0 & 9.3 & 3.0 \\
\hline Mach Number & $M_{\infty}$ & & 0.4 & 0.25 & 0.25 & 0.25 \\
\hline Spray Time & $t$ & $\mathrm{~min}$ & 6 & 2 & 2 & 3 \\
\hline Angle of Attack & $\alpha$ & $\mathrm{deg}$ & -6 & -6 & -6 & 0 \\
\hline
\end{tabular}

9

American Institute of Aeronautics and Astronautics 
For Run 530 the initial $T_{w b, 0}$ was set to be $3{ }^{\circ} C$. After 3 minutes of IWC only spray, no ice formation was observed on the test article surface. The surface thermocouple reading from the wedge model leading edge in time average was around $4.0^{\circ} \mathrm{C}$. Applying the Run 530 test condition to Eq. (8) it was shown that with $T_{w b, 0}=3{ }^{\circ} \mathrm{C}$, $V W C_{\text {gain }}=0.935 \mathrm{~g} / \mathrm{m}^{3}, M R=0.3$, and estimated $n_{\text {loss }}=0.90$, the $I W C$ threshold is approximately

$$
I W C^{*}=3.8 \mathrm{~g} / \mathrm{m}^{3} \text {. }
$$

Since the $I W C_{i}$ value is less than the threshold, no ice would survive (i.e. $m_{0}=1$, all melted). However if one let the $I W C_{i}$ be greater than the threshold, some ice build-up should remain on the surface. This was exactly the rationale behind Run 522. It was a 2 minutes of $I W C_{i}$ only spray with everything the same as Run 530 except $I W C_{i}=$ $17 \mathrm{~g} / \mathrm{m}^{3}$ and $\alpha=-6 \mathrm{deg}$. For Run $522 \mathrm{a}$ large ice formation with frequent ice shedding and growing was observed on the wedge airfoil surface at the same $T_{w b, 0}=3^{\circ} \mathrm{C}$, see Fig. 3 .

Further, one could ask if it were possible to turn off this large ice build-up process completely by raising the air total wet bulb temperature. This was the design objective for Run 524 in which the $T_{w b, 0}$ was raised from 3 to 9.3 ${ }^{\circ} \mathrm{C}$. The large ice build-up completely vanished and became surface runback water (see Fig. 3). The thermocouple reading for this case in time average was around $7.0^{\circ} \mathrm{C}$. Applying the Run 524 condition to Eq. (9) it was shown that with $T_{w b, 0}=9.3^{\circ} \mathrm{C}, V W C_{\text {gain }}=0.967 \mathrm{~g} / \mathrm{m}^{3}, M R=0.41$, and estimated $n_{\text {loss }}=0.90$, the $T_{w b, 0}$ threshold is about

$$
T^{*}=7.9{ }^{\circ} \mathrm{C}
$$

Since the $T_{w b, 0}$ value now is much warmer than the threshold $T^{*}$, all ice should be melted on the surface according to the model estimates and the test data confirmed that there was no ice remaining on the wedge model surface.

\section{B. NASA PSL Ice Crystal Icing Engine Test - Full Engine Flow Simulation}

A known AlliedSignal ALF 502-R5 turbofan engine RB condition, FLT 850, was chosen as the baseline for this analysis. Due to very limited number of instruments installed in the engine LPC region for the 2013 PSL engine icing test, some local flow details of the ALF 502-R5 LF01 engine in FLT 850 condition were extracted from the baseline test data DP 443 or were calculated from COMDES/MELT, Glenn-HT and LEWICE3D simulations if the needed information was not available. In the analysis the main icing site under consideration is the $2^{\text {nd }}$ exit guide vane stator leading edge (i.e. EGV2 LE).

The proposed key connection to a full engine RB event is that if ice crystal icing were sustained in EGV2 LE a RB event would occur for this engine and the stronger this ice build-up process were in EGV2 LE the quicker the RB event would occur. On the contrary, if icing is not allowed in EGV2 LE then no engine RB event would likely take place.

Table 2 displays a number of FLT 850 related test conditions that were selected for the comparison and the test conditions are all scaled by the baseline, DP 443. From the table one clearly can see how the change in IWC, N1 or $T_{\infty}$ could affect the engine RB phenomenon. The PSL test data showed that an engine RB event can be turned off completely by reducing the IWC load like DP 574, or by increasing the fan speed N1 like DP 735, or by raising the ambient air temperature $T_{\infty}$ like DP 740. The engine RB event can also be further enhanced by increasing the IWC intake like DP 577. It should be noted that the DP 729 is another FLT 850 baseline variant with $57 \%$ of the baseline IWC value that has experienced a slower called RB event.

For the first four test conditions in Table 2 Eq. (7) was used to determine the ice mass flux threshold. However the actual ice mass flux at EGV2 LE location was approximated from the combined Glenn-HT and LEWICE3D simulations. The final results were all scaled by the ice/water mass flux threshold of the baseline, DP 443, for data sanitization purpose.

Table 2 FLT 850 related test conditions in 2013 PSL engine icing test

\begin{tabular}{|c|c|c|c|c|c|c|c|c|}
\hline Description & D P & Alt & $M_{\infty}$ & $T_{\infty}$ & $N 1$ & $I W C$ & RB (Y, N) & RB (Y, N) Call Time \\
\hline FLT 850 & 443 & 1 & 1 & 1 & 1 & 1 & Y & 1 \\
\hline & 574 & 1 & 1 & 1 & 1 & 0.33 & N & 7.1 \\
\hline & 577 & 1 & 1 & 1 & 1 & 1.23 & Y & 0.9 \\
\hline & & & & & & & & \\
\hline FLT 850-1 & 729 & 1 & 1 & 1 & 1 & 0.57 & Y & 1.7 \\
\hline & 735 & 1 & 1 & 1 & 1.06 & 0.57 & N & 6.9 \\
\hline & 740 & 1 & 1 & 1.02 & 1 & 0.57 & N & 3.8 \\
\hline
\end{tabular}


Similarly for the last two test conditions in Table 2 Eq. (9) was used to calculate the $T_{w b, 0}$ threshold. To determine the local air total wet bulb temperature $T_{w b, 0}$ the local surface temperature measurement data at EGV1 and EGV2 were also analyzed to find the estimate. The values were again scaled by the baseline $T_{w b, 0}$ threshold. The calculated results were tabulated in Table 3. It was noticed that for each RB event test condition there was ice buildup at EGV2 LE from the model prediction, and similarly for each non RB event condition no ice was allowed to form at EGV2 LE.

Table 3 The model analysis results

\begin{tabular}{|c|c|c|c|c|}
\hline Data Point & Location & $\dot{m}_{i m p, t}$ & $\dot{m}_{i m p, t}^{*}$ & Icing (Y, N) \\
\hline 443 & EGV2 LE & 1.74 & 1 & $\mathrm{Y}$ \\
\hline 574 & EGV2 LE & 0.57 & 1 & $\mathrm{~N}$ \\
\hline 577 & EGV2 LE & 2.14 & 1 & $\mathrm{Y}$ \\
\hline 729 & EGV2 LE & 1.00 & 1 & $\mathrm{Y}$ \\
\hline & & & & Icing (Y, N) \\
\hline Data Point & Location & $T_{w b, 0}$ & $T^{*}$ & $\mathrm{~N}$ \\
\hline 735 & EGV2 LE & 1.003 & 1 & $\mathrm{~N}$ \\
\hline 740 & EGV2 LE & 1.006 & 1 & \\
\hline
\end{tabular}

As stated in the beginning of this comparison, it was believed and hypothesized by the first author that ice crystal icing occurring at EGV2 LE location is directly tied to the formation of an engine RB event. The preliminary results from the model analysis seem to agree well with the PSL engine icing test data trend. This would indicate there is a strong connection between the local ice formation inside an engine LPC at EGV2 LE and the engine RB phenomenon.

\section{Conclusion}

A thermodynamic model is developed to describe possible mechanisms of ice formation on unheated surfaces inside a turbofan engine compression system from fully glaciated ice crystal clouds. It is shown from the analysis that, in general, there could be two distinct types of ice formation: (1) when the surface is dominated by the freezing of water melt from fully or partially melted impinging ice crystals, the ice structure is formed from accretion with strong adhesion to the surface, and (2) when the surface is instead dominated by the further melting of ice crystals, the ice structure is formed from accumulation of un-melted ice crystals with relatively weak bonding to the surface. The model is able to capture important qualitative trends of the fundamental ice-crystal icing phenomenon reported early from the research collaboration work by NASA and the National Research Council (NRC) of Canada.

In addition, preliminary model analyses are performed to compare the model's estimates with selected data from the 2013 full scale ALF 502-R5 LF01 turbofan engine ice crystal icing test conducted in the NASA Glenn PSL. The preliminary results showed that the model is able to capture important qualitative trend of turning on (or off) the ice crystal ice formation in the engine low pressure compressor EGV2 LE area under different icing conditions that ultimately lead to (or suppress) an engine core roll back (RB) event. Detailed analyses on other interesting test data from the PSL test matrix, e.g. the FLT 855 no RB test point and six revenue service RB field event test points designated as RS-1 to RS-6 in Ref. 3, will be performed to assess the overall validity and effectiveness of the proposed model. New altitude scaling methods derived from this model for simulating ice crystal accretion inside a turbofan engine will be developed and evaluated in PSL in the coming NASA engine icing test.

\section{Acknowledgments}

This work is supported by the Atmospheric Environment Safety Technology Project (AEST) in the NASA Aviation Safety Program, and is in response to the Engine Icing Technical Challenge. The first author is supported currently under a NASA Glenn ARTS contract. Special thanks are extended to Dr. Ron Colantonio and Mr. Thomas Bond for their support of the work. The first author also wishes to acknowledge the help and guidance he received from Mr. Joe Veres (The Engine Icing Technical Lead) for providing the general aero-thermodynamic flow simulation of the overall engine system from the Honeywell Engines customer deck (CD) and COMDES/MELT, Dr. David Rigby (Vantage Partners, LLC) for providing the detailed engine LPC local flow simulation from Glenn-HT and Mr. Colin Bidwell for providing the detailed ice particle trajectory and phase change information from the LEWICE3D simulation. 


\section{References}

${ }^{1}$ Struk, P., Currie, T., Wright, W. B., Knezevici, D. C., Fuleki, D., Broeren, A., Vargas, M. and Tsa o, J. C., "Fundamental Ice Crystal Accretion Physics Studies," SAE 2011 International Conference on Aircraft and Engine Icing and Ground Deicing, SAE 2011-38-0018, June 2011 or NASA/TM-2012-217429, 2012.

2 Currie, T. C., Struk, P. M., Tsao, J. C., Fuleki, D. and Knezevici, D. C., "Fundamental Study of Mixed-Phase Icing with Application to Ice Crystal Accretion in Aircraft Jet Engines," AIAA-2012-3035, June 2012

3 Oliver, M., "Inaugural Ice Crystal Icing Engine Test in the Propulsion Systems laboratory at NASA Glenn Research Center," abstract CID\# 1888452, to be presented in AIAA Aviation 2014 ASE Conference, June 2014.

${ }^{4}$ Mason, J.G., Strapp, J.W. and Chow, P., "The Ice Particle Threat to Engines in Flight,” AIAA-2006-0206, January 2006.

5 Kamel Al-KHalil, "Assessment of Effects of Mixed-Phased Icing Conditions on Thermal Ice Protection Systems," DOT/FAA/AR-03/48, May 2003.

${ }^{6}$ Veres, J. P., Jorgenson, P. C. E., "Modeling Commercial Turbofan Engine icing Risk with Ice Crystal Ingestion," AIAA2013-2679, June 2013.

7 Veres, J. P., Jorgenson, P. C. E., "Modeling Commercial Turbofan Engine with Ice Crystal Ingestion; Follow-on," abstract CID\# 1893152, to be presented in AIAA Aviation 2014 ASE Conference, June 2014.

${ }^{8}$ Struk, P. M., Bencic, T., Tsao, J. C., Fuleki, D. and Knezevici, D. C., "Preparation for Ice-Crystal Icing Scaling Studies at the NRC Research Altitude Test Facility,” AIAA-2013-2675, June 2013

${ }^{9}$ Ruff, G.A., “Analysis and Verification of the Icing Scaling Equations,” AEDC-TR-85-30, Vol 1 (rev), March 1986.

${ }^{10}$ Anderson, D. N., "Manual of Scaling Methods," NASA /CR-2004-212875, March 2004.

11 Anderson, D. N. and Tsao, J. C., "Ice Shape Scaling for Aircraft in SLD Conditions," NASA/CR-2008-215302, DOT/FAA/AR-07/55, September 2008.

12 Tribus, Myron, Young, G.B.W. and Boelter, L.M.K., “Analysis of Heat Transfer Over a Small Cylinder in Icing Conditions on Mount Washington," Trans. ASME, vol. 70, November 1948, pp 971 - 976. 